\title{
Analyzing the Efficiency of Response to News Regarding Legalization of Sports Wagering
}

Kevin Krieger ${ }^{a *}$ and Justin L. Davis ${ }^{\mathrm{b}}$

${ }^{a}$ Department of Accounting and Finance, University of West Florida, Pensacola, FL, USA;

${ }^{b}$ Department of Management and MIS, University of West Florida, Pensacola, FL, USA

* 11000 University Pkwy, Building 76, Pensacola, FL 32514 kkrieger1@uwf.edu 


\section{Analyzing the Efficiency of Response to News Regarding Legalization of Sports Wagering}

Abstract

A landmark decision (Murphy v. NCAA) by the Supreme Court of the United States (SCOTUS) in 2018 ruled the federal government could not prohibit states from allowing sports wagering. While the implications of this decision are far reaching at both an industry and societal level, our study assesses the market response to information available throughout the various phases leading up to this decision by SCOTUS. The timeline of events preceding the SCOTUS decision is tracked, and stock performances of relevant, publicly traded firms are analyzed across three inflection points. Findings suggest the market failed to adequately acknowledge key events indicating the likelihood of the eventual decision by SCOTUS, instead only responding once its formal ruling was released on the final decision date. These findings raise questions about the efficiency of markets reacting to available information and the potential for investors to profit in similar future situations.

Keywords: Sports Gambling, Sports Betting, Supreme Court, Market Efficiency 


\section{Introduction}

On May $14^{\text {th }}, 2018$, the Supreme Court of the United States (SCOTUS) voted to strike down as unconstitutional the Professional and Amateur Sports Protection Act (PASPA) that had been enacted in 1992, effectively removing federal regulation of sports gambling in the United States (U.S.). This decision came in the wake of a lengthy legal battle between the state of New Jersey and professional and collegiate sports leagues. The effect of the removal of PASPA will only be realized over time, but the impact on business and sport organizations has been immediate. While this decision creates a regulative jolt in what had recently been a relatively stable industry, the factors influencing and leading up to this action had been developing methodically in the months, if not years leading up to SCOTUS' final decision.

Over the last two decades, sports gambling has seen tremendous growth in both legal and illegal settings. In 1999, estimates of the size of the total (legal and illegal combined) sports gambling market by the American Gaming Association were very broad, ranging from $\$ 80$ billion to $\$ 380$ billion and illustrating the uncertainty surrounding the size of this market, in large part due to the lack of regulation. However, this industry has become slightly more transparent in recent years as legal battles have played out. In 2017, the Nevada Gaming Control Board reported legal wagers in the amount of $\$ 4.9$ billion, with revenue totaling $\$ 248.7$ million. In addition, a 2017 filing with SCOTUS by the American Gaming Association estimated that illegal sports gambling in the U.S. measured in excess of $\$ 150$ billion annually. Additionally, projections suggest growth in legal sports gambling revenue in the U.S. may increase $24 x$, by 2023, to an amount exceeding \$6 billion annually following the removal of PASPA. ${ }^{1}$ While

\footnotetext{
${ }^{1}$ https://www.sportsbusinessdaily.com/Journal/Issues/2018/04/16/World-Congress-of-Sports/Research.aspx
} 
these are just projections, the impact of legalization of sports wagering on the U.S. gaming industry has almost exclusively been predicted to be positive for companies with involvement in gaming.

While high growth is expected with the widespread legalization of sports gambling, ${ }^{2}$ the question for the years leading up to this landmark SCOTUS decision was when or if legalization would ever occur, with the expectation that PASPA could, but potentially would not, remain valid federal law forever (Wyant 2017). The events leading up to this regulative change via PASPA's invalidation are the focal points of the current study. The road toward PASPA's invalidation was involved, with the events leading up to the decision by SCOTUS taking place over a period of many years (see Figure 1). Most notably, starting with its agreement to consider Murphy v. NCAA, SCOTUS gave indications of its likely, eventual leaning on this issue. In fact, in the months leading up to the 2018 decision overturning PASPA, prediction markets were rather explicit in their expectations, and these markets were eventually proven correct.

Specifically, in this study, we analyze three key points in time during the process of the judicial review of PASPA which culminated in its overturning. These are: 1) the date that SCOTUS announced it would hear the case against PASPA (granting a writ of certiorari), 2) the SCOTUS hearing date (oral argument), and 3) the SCOTUS decision date (issuing of an opinion). We assess the impact of each event, including the market response as indicated by relevant industry players that might be significantly impacted by a change in the law. We also consider various subgroups of organizations within the gaming industry in order to highlight any specific situations where the impact of the invalidation of PASPA would potentially be stronger

\footnotetext{
${ }^{2}$ Following PASPA's invalidation, and as of this writing, legal sports wagering is permissible in New Jersey, Delaware, Pennsylvania, West Virginia, and New Mexico. Other states are already considering legalization as well.
} 
or weaker. Our findings raise interesting questions about the practical nature of the efficient market hypothesis. Implications and discussion of these findings follow.

\section{Background and Development}

Standard market efficiency theory suggests that newsworthy events will fully, immediately, and correctly be incorporated into the prices of assets which they impact. While experts generally believe that widespread information is quickly incorporated into prices (see, e.g., Fama 1998), and that it is difficult to utilize breaking information for profit, the mechanics of such "efficiency" vary from situation to situation. Some first movers must actually change asset prices by applying information, and in the case of stock prices, shareholder values change accordingly. In our study, we consider the application of market efficiency regarding news of potential state legalization of sports wagering in the United States, made possible after the invalidation of federal law prohibiting such state actions. This news surrounds SCOTUS' decision to consider, and ultimately invalidate PASPA in 2017 and 2018. Three unique events highlight this development. First, on June $27^{\text {th }}, 2017$, SCOTUS agreed to hear the case Murphy $v$. $N C A A$. This agreement legitimized the possibility of striking down federal legislation prohibiting sports wagering. Next, on December $4^{\text {th }}, 2017$, SCOTUS heard oral arguments in the case, and the tone and content of their questions to litigants suggested to experts (who immediately shared their opinions with the public and press) that PASPA was likely to be invalidated. Finally, on May $14^{\text {th }}, 2018$, SCOTUS struck down PASPA in its formal opinion (decision) in Murphy $v$. $N C A A$ thereby removing barriers at the federal level, and allowing interested states to pursue legalization.

These three developments were all considered by experts to be increasingly likely opportunities for a number of publicly traded companies that might operate in the sports 
wagering industry. ${ }^{3}$ In this study, we consider the empirical question of which of these events, if any, actually saw an impact on the stock prices of the aforementioned companies on the three event days in question. Might all three noteworthy days be considered equally important/significant in conveying information to the market? Or is one event more (or less) important than another?

Immediately upon the grant of certiorari, experts noted that PASPA might be invalidated and some companies might profit (see, e.g., The Washington Post ${ }^{4}$, which calls SCOTUS' grant of certiorari "surprise" news. Also see, e.g., USA Today ${ }^{5}$. Did stock prices indeed react "efficiently" to this positive surprise? Once arguments in Murphy v. NCAA were heard in front of SCOTUS, experts noted, that same day, that PASPA was likely to fall, and this might change the landscape of the sports wagering industry (see, e.g., articles dated December $4^{\text {th }}, 2017$, from ScotusBlog${ }^{6}$ and The New York Post ${ }^{7}$. Did stock prices indeed react "efficiently" to this news? And, upon PASPA's formal invalidation, with the issuing of the SCOTUS opinion striking down PASPA, experts noted the opportunities for companies in the sports wagering industry (see, e.g., Bloomberg $^{8}$ ). Did stock prices indeed react efficiently to this final news?

Herein we study these subparts of the invalidation of PASPA, allowing for legalized, statewide sports wagering. While experts saw all three of the aforementioned developments as

\footnotetext{
${ }^{3}$ Indeed, real-time prediction markets considering the specific question of whether SCOTUS would invalidate PASPA see dramatic changes on the dates in question. See, for example: https://www.predictit.org/Contract/8748/Will-Supreme-Court-rule-against-federal-sports-betting-ban\#data https://goodjudgment.com/superforecasting/index.php/2018/05/16/murphy-v-ncaa-betting-on-the-crowd/

${ }^{4}$ https://www.washingtonpost.com/news/early-lead/wp/2017/06/27/in-surprise-move-supreme-court-says-it-willtake-on-new-jersey-sports-betting-case/?noredirect $=$ on\&utm_term $=. d 58$ ae8ee5160

${ }^{5} \mathrm{https}$ //www.usatoday.com/story/sports/2017/06/27/u-s-supreme-court-decision-sports-betting-casecongress/431528001/

${ }^{6}$ http://www.scotusblog.com/2017/12/argument-analysis-justices-seem-side-state-sports-betting/

${ }^{7} \mathrm{https}$ ://nypost.com/2017/12/04/supreme-court-indicates-support-for-nj-sports-gambling/

${ }^{8} \mathrm{https}$ //www.bloomberg.com/news/articles/2018-05-14/federal-sports-wagering-ban-struck-down-by-u-s-supremecourt
} 
each increasing the likelihood of the final outcome (PASPA's invalidation), the actual market efficiency dynamics of incorporating the information are empirical considerations for study. In this paper we consider these questions using a full sample of stocks in the sports wagering industry that were noted as potential beneficiaries in financial news stories. In addition, we consider whether some types of companies operating in the sports wagering industry (subgroups of our full sample) might recognize greater windfalls from news than others.

\section{Methods}

To consider the impact of SCOTUS invalidating PASPA, we collect data on a full set of 12 publicly traded companies with daily returns and volume data available for download via Yahoo! Finance. The 12 companies we consider operate casino and/or electronic gaming endeavors in the United States and would be poised, if legalization were to occur, to offer sports betting services. We recognize that our full list is not exhaustive of companies that could profit from legalization of sports gambling in various states, following the invalidation of PASPA; however, we develop the list by reading popular financial press articles in the wake of SCOTUS' grant of certiorari on June $27^{\text {th }}, 2017$, and noting all stocks that journalists and analysts explicitly anticipated potentially benefiting from legalization. The sources of our reading include, but were not limited to: The Wall Street Journal, CNBC.com, investors.com, ESPN Business, and bettingUSA.com. ${ }^{9}$ Other unlisted sources consistently referenced the companies noted from the above, named sources, and did not explicitly list other publicly traded gaming stocks.

[Insert Table 1 near here]

\footnotetext{
9 This blog explicitly covers news regarding American gaming stocks.
} 
Furthermore, we consider 6 subgroups of our full sample of 12 gaming stocks with each subgroup representing between 2 and 7 stocks. The first four subgroups were each presented as a group of potential beneficiaries of sports gaming legalization by one of the financial press sources named above. In particular, Subgroup 1 and Subgroup 2 were noted as emphasizing regional players explicitly noted by the press. For example, as noted at investors.com ${ }^{10}$ :

"...analysts have said the difference between expectations and reality means it may not be the revenue bonanza for casino stocks such as of Las Vegas Sands (LVS), Wynn Resorts (WYNN) and MGM Resorts (MGM) than it first appears. In fact the biggest winners should actually be the strong regional players, such as Caesars Entertainment (CZR), Boyd Gaming (BYD) and Penn National Gaming (PENN). With their vast network of properties, they are the best poised to open sports books around the U.S., especially if states opt to limit the locations where such betting is allowed."

Subgroup 3 considers stocks that a financial blogger who emphasizes gaming notes as potentially benefiting from PASPA's invalidation, and Subgroup 4 emphasizes over-the-counter stocks tied to overseas companies with a significant footprint in American gaming. Additionally, we construct two more subgroups of stocks based on pure rankings of financial information. Specifically, Subgroup 5 contains the 5 highest grossing US gaming revenue stocks of the 12member full set ${ }^{11}$, and Subgroup 6 contains the 4 stocks with the highest $\%$ of revenue derived

\footnotetext{
10 https://www.investors.com/research/ibd-industry-themes/supreme-court-legalize-sports-bettingcasinos/

${ }^{11}$ We elect to cut off the sample at five stocks as the drop in US gaming revenue from the fifth stock of the full sample (BYD), to the sixth (IGT), is greater than the gap between the leading stock (MGM) and BYD.
} 
from US gaming. ${ }^{12}$ More detail on the full group of stocks analyzed, as well as the motivation for the construction of each subgroup is available in Table 2.

[Insert Table 2 near here]

We consider event-day impacts of SCOTUS' potential action to invalidate PASPA on three meaningful dates. ${ }^{13}$ First, we consider whether sports gaming stocks react to news of SCOTUS' decision to hear the relevant case challenging PASPA, Murphy v. NCAA, on June $27^{\text {th }}$, 2017. Formally, this process is conducted via SCOTUS' grant of a writ of certiorari which requires a minimum of four votes of the nine SCOTUS justices to elect to hear the case. Commentators generally consider the grant of the writ to be a positive indicator that the appellant (in this case, Murphy, seeking the invalidation of PASPA) may have support before the Court. In fact, from 2013-2017, 70\% of the cases heard by SCOTUS reversed rulings in favor of the party seeking action, and in 2016 only 17\% (9 of 54) of cases were affirmed by SCOTUS. The news of grant of certiorari may be viewed as an ideal event for consideration with event study methodology, as we do here, spanning across a number of sports gaming stocks and subgroups. The anticipation would be a positive event impact on stocks tied to sports gaming. ${ }^{14}$

SCOTUS cases typically involve one hour of oral argument in front of the nine justices in which the justices engage counsel of both sides of a case with questions. At times, "questions" are more declarative than inquisitive and are sometimes tailored toward fellow justices. The tone of justice questions and comments is often thought to be enlightening regarding eventual votes of

\footnotetext{
12 We elect to cut off the sample at four stocks as the drop in \% of revenue from US gaming from the fourth stock of the full sample (CHDN), to the fifth (CZR), is greater than the gap between the leading stock (PNK) and CHDN.

${ }^{13}$ Additionally, we consider multi-day impacts on our gaming stock prices after SCOTUS action, but we generally find meaningful impacts are captured on the event day (0), and event-day tests provide superior statistical power, so we focus on these herein.

${ }^{14}$ https://www.legalsportsreport.com/14481/scotus-may-grant-nj-sports-betting-appeal/ (note: "This (upcoming) Monday" in question is Monday, June $27^{\text {th }}, 2017$, the first of our three event days.
} 
individual justices, and often justices all but portend their eventual position on cases via their comments. Murphy v. NCAA was argued in front of the Court on December $4^{\text {th }}, 2017$. While live audio and visual recordings of SCOTUS proceedings are not available, many journalists and analysts attend SCOTUS arguments and quickly report justice comments and share their impressions of cases. ${ }^{15}$ Observers generally found SCOTUS more likely to side with the appellant (Murphy) and likely to strike down PASPA based on oral arguments. ${ }^{16}$ Thus, we employ our event-study methodology to consider the efficiency of sports gaming stock prices to these developments. Given the impressions of observers, we would anticipate a positive reaction in the prices of sports gaming stocks.

Finally, we consider the actual date of SCOTUS' final decision in Murphy v. NCAA, May $14^{\text {th }}, 2018$, on which SCOTUS did indeed, by a 6-3 vote, invalidate PASPA, thus allowing for individual states to legalize sports wagering if they should choose to do so. ${ }^{17}$ As we previously noted, this was widely considered the most likely final result of the case, particularly given the grant of certiorari and the developments of oral argument. However, the ruling was not definitive until the day of SCOTUS' opinion. For a third time, we employ our event-study methodology to consider the efficiency of sports gaming stock prices to the news of possible legalization. Again, we anticipate a positive event reaction, if any.

In this study, our overall effort is to determine the event impacts of news regarding possible legalization of sports gaming. Does such news, emanating from SCOTUS, drive an (anticipated positive) impact? Furthermore, if such impacts are present, are they manifested at the time of certiorari grant? Are they manifested when oral argument suggests PASPA is likely

\footnotetext{
${ }^{15}$ Transcripts of oral arguments are generally available shortly following a case's argument as well.

${ }^{16} \mathrm{http}$ ://www.scotusblog.com/2017/12/argument-analysis-justices-seem-side-state-sports-betting/

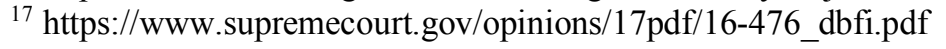


to be invalidated $?^{18}$ Are they manifested when SCOTUS' decision is final? In an efficient market, all three of these events would prove noteworthy as the likelihood of legalization increases with each of them (for example, say, jumping from an initial $0 \%$ to $50 \%$ then to $75 \%$ then to $100 \%$ on June $27^{\text {th }}, 2017$, December $4^{\text {th }}, 2017$, and May $14^{\text {th }}, 2018$, respectively). The actual impact on sports gaming stock prices in response to SCOTUS' involvement with PASPA is an empirical question that we document here. Additionally, as various predictions are made regarding specific types of sports gaming stocks which might most benefit from PASPA's invalidation, we consider the performances of our various subgroups on the three event days in question.

To measure performance of sports gaming stocks in response to SCOTUS-PASPA events, we construct abnormal returns of each of our 12, full-sample sports gaming stocks. We do so via two different methods. We first consider a market model which corrects daily returns of all 12 stocks for daily S\&P 500 performance via a $(-121,-1)$ day estimation window. We then consider a similar approach which utilizes the same $(-121,-1)$ day estimation window but calculates abnormal returns based on three Fama-French (1993) factors, utilizing coefficient estimates from the estimation window combined with daily Market, Small-Minus-Big (SMB), and High-Minus-Low (HML) portfolio performance as archived on Ken French's website. ${ }^{19}$

We present the average, event-day abnormal returns for all three events in Tables 3-5, respectively. We do so for our full sample of 12 sports gaming stocks, as well as the 6 subgroups discussed in Table 2. We consider abnormal returns calculated both via the market model and the Fama-French approach. To test for statistical significance, we employ the rank-test methodology of Corrado (1989). This non-parametric approach corrects for the cross-sectional

\footnotetext{
${ }^{18} \mathrm{https}: / /$ sportshandle.com/supreme-court-paspa-sports-betting-predictions/

${ }^{19} \mathrm{http} / / /$ mba.tuck.dartmouth.edu/pages/faculty/ken.french/Data_Library/f-f_factors.html
} 
correlation effect permeating our study as each of the three events in question occurs across all of our gaming stocks on simultaneous event days. The Corrado (1989) approach considers the abnormal returns (market-model or Fama-French based) and how unusual event-day performances of the stocks are, given these corrections, and its test statistic assumes the traditional Z-distribution.

Additionally, to indicate the intensity of trading, for each event day we record average trading volume of the full sample of gaming stocks and the various subgroups, each relative to its average daily trading volume over the 120 days prior $(-121,-1)$. In these illustrations, if a stock has a perfectly average amount of trading volume on an event day (for example, a volume of 100,000 on the event day, when the daily average over the prior 120 days was also 100,000 ), then the "\% volume" noted in our tables would be $100 \%$.

\section{Results}

The first of three events advancing a likelihood of PASPA's invalidation by SCOTUS was SCOTUS' decision to grant the writ of certiorari in Murphy v. NCAA on June $27^{\text {th }}, 2017$. While this event was widely acknowledged as meaningful in the sports wagering industry, sports wagering stocks did not respond to the event with the predicted, positive reaction.

\section{[Insert Table 3 near here]}

Table 3 shows that the average abnormal market return to our full sample of 12 sports gaming stocks, subsequently noted in the financial press, was actually negative on June $27^{\text {th }}$, 2017. This is the case even though we selected our full sample of sports wagering stocks in part based on conjecture in the financial press on this date! While the average response was very small in magnitude and statistical significance, it certainly did not lend evidence to a textbook 
efficient market incorporating positive news. The results for each of our six subgroups, intended to measure the performances of specific parts of the publicly traded sports gaming industry, find no positive significant results either. In fact, the only statistical significance detected is in the negative direction for Subgroup 6 when utilizing Fama-French abnormal returns. Additionally, trading volume of sports wagering stocks was practically unchanged from that seen on an average day. The totality of evidence strongly suggests that, while experts knew this may be a landmark development, the market did not view the grant of certiorari in Murphy v. NCAA as financially meaningful. Given that eventual invalidation of PASPA has been seen as a windfall for at least some companies in the sports wagering industry, this seems indicative of market oversight/inefficiency.

The second of three events advancing the likelihood of PASPA's invalidation by SCOTUS was the oral argument of December $4^{\text {th }}, 2017$. Immediately in the wake of that morning's argument, experts and the press described SCOTUS' skepticism of the constitutionality of PASPA and all but predicted its eventual invalidation. This could be seen in popular outlets, such as USA Today $^{20}$ (note the story's time of publication of 1:42pm ET) as well as in online prediction markets. ${ }^{21}$ Stock prices of the aforementioned sports wagering companies, however, were not impacted, as seen in Table 4.

\section{[Insert Table 4 near here]}

The average abnormal stock return to our 12 industry stocks is small and insignificant, though positive, for this event. Only one subgroup (Subgroup 3) demonstrates any degree of statistical significance. This 70 basis point abnormal return, based on Fama-French construction,

\footnotetext{
${ }^{20}$ https://www.usatoday.com/story/news/politics/2017/12/04/supreme-court-could-make-sports-bettingban-underdog/919347001/

${ }^{21}$ For example: https://goodjudgment.com/superforecasting/index.php/2018/05/16/murphy-v-ncaabetting-on-the-crowd/
} 
is significant at the $5 \%$ level. However, given the number of individual tests conducted, basic Type-I error might be expected to yield around one "false positive" result in our measurements. Trading volume, again, does not appear much greater on SCOTUS' argument day than on a typical trading day. In fact, our full sample of 12 industry stocks actually shows lower trading volume on argument day than on the average day. The totality of evidence, again, strongly suggests that, while experts were predicting eventual opportunities for sports wagering companies on the horizon, investors did not use this information in a way consistent with the traditional theory of market efficiency immediately incorporating news.

The actual invalidation of PASPA, given SCOTUS' opinion issued on May $14^{\text {th }}, 2018$, impacted the values of sports wagering stocks much more strongly than the "non-events" reflected by prices on the certiorari and argument days. Table 5 illustrates these impacts.

[Insert Table 5 near here]

The event-day, average abnormal return using the market model (Fama-French model) is an impressive $4.72 \%$ (4.81\%). This result is statistically significant at the 5\% level. Trading volume across our full sample of 12 stocks is $57.73 \%$ higher on the day of SCOTUS' decision than on an average trading day.

The average abnormal return results of most subgroups are positively significant as well. Subgroup 1, noting one list of potential "winner" companies with regional gaming expertise posts a significant $5.55 \%$ market-model (5.68\% Fama-French-model) abnormal return on the event day. Subgroup 2 considers another potential group of gainers with regional gaming expertise and finds a significant $4.31 \%(4.40 \%)$ abnormal return as measured by the market model (Fama-French model) on event day. Subgroup 4 concentrates on the American shares of two international gaming stocks which might increase US operations upon state legalization of 
sports wagering. The average abnormal event-day return is a massive, significant $13.39 \%$ (13.48\%) when abnormal returns are calculated via the market model (Fama-French model). Subgroup 5 consists of the five companies from our full sample with the highest US gaming revenue in 2017 , and the significant, average abnormal event-day return is $3.26 \%(3.32 \%)$ as measured by the market model (Fama-French model). Subgroup 6 considers the four stocks from our full sample with the highest percentage of revenue derived from US gaming operations, and in this subgroup we find a significant, average abnormal event-day return of 3.54\% (3.66\%) when abnormal returns are measured via the market model (Fama-French model). Furthermore, the average subsample volumes on the event day of SCOTUS' decision are considerably greater than on a typical trading day. These range from Subgroup 5, with an event-day volume $177.72 \%$ higher than the average day, to Subgroup 3, with an event-day volume $387.73 \%$ higher than the average day.

\section{Discussion}

In summary, our analysis reveals a somewhat surprising timeline for the incorporation of relevant information into the stock prices of sports wagering companies. Specifically, the potential for major changes in the American sports wagering industry was afoot on June $27^{\text {th }}$, 2017 when SCOTUS agreed to hear Murphy v. NCAA. This development immediately put forth real potential for the eventual invalidation of PASPA and, thus, the legalization of sports wagering by some states. These developments were widely and immediately reported, but stock prices of our sample of sports wagering companies did not respond at all to this news. ${ }^{22}$ This is a curious result, conflicting the most obvious predictions of market efficiency. While the exact likelihood of eventual legalization was unknowable at the time, it certainly changed from $\sim 0 \%$,

\footnotetext{
${ }^{22}$ Multi-day abnormal returns exhibit even lower magnitude and statistical significance than those reported above.
} 
on the prior day, to nonzero. To see no impact on sports wagering company stocks is both surprising and contrary to the efficient market hypothesis.

A similar result materialized on December $4^{\text {th }}, 2017$ when oral argument was conducted before SCOTUS. Court watchers, legal experts, and financial analysts immediately fancied the likelihood of PASPA's invalidation when they listened to the questions and comments of SCOTUS justices. These expectations were publicized almost immediately by wide-reaching news outlets, and transcripts of the actual arguments were also almost immediately available. Nevertheless, the stock prices of our sample of sports wagering companies were unaffected by the news. ${ }^{23}$ This is another curious result, inconsistent with the basic expectations of efficient markets, particularly in an age of far-reaching, instant communication. While the exact increase in the likelihood of PASPA's eventual invalidation was unknowable on the day of SCOTUS argument, there is widespread agreement that this likelihood substantially increased and a survey of prediction markets specialists placed expectations of overturning PASPA in the $75-80 \%$ range following the hearing of these arguments, an upswing from earlier levels. ${ }^{24}$

Instead of the stepwise implementation of information making PASPA's invalidation more likely, we see almost all gaming stock price impact on the final, actual SCOTUS decision day of Murphy v. NCAA. We detect rather sizable, significant event-day abnormal returns, ranging from $3 \%$ to $5 \%$ across our full sample and most of our subgroups. It appears that, indeed, the market did value the invalidation of PASPA as an important, value-changing event for our sample of stocks from sports wagering companies. However, instead of incorporating this event in the predictable, theoretical way in which market efficiency theory would suggest (namely, via

\footnotetext{
${ }^{23}$ Multi-day abnormal returns exhibit even lower magnitude and statistical significance than those reported above.

${ }^{24}$ https://goodjudgment.com/superforecasting/index.php/2018/05/16/murphy-v-ncaa-betting-on-the-crowd/
} 
stepwise increases reflecting increasing event probabilities) it seems the entire impact was practically delivered when SCOTUS' decision was final, as if the probability of PASPA increased from $0 \%$ to $100 \%$ instantaneously, rather than predictably. This timeline of implementation of information suggests a great opportunity for investors who were willing to consider the developments in the Murphy v. NCAA case and react contemporaneously by updating probabilities and implied prices. The actual path of sports wagering stock prices suggests there were few such "informed" investors, at least with the funds or conviction necessary to impact the prices in a way that advocates of market efficiency might expect on the certiorari or oral argument days.

The most pressing question, going forward, is whether our results portend widespread opportunities for investors to incorporate news and gain abnormal returns. If so, in what areas might these opportunities exist? Some past researchers have provided an explanation for underreaction to new information, attributing the lack of response to things such as investor psychological or cognitive behaviors (e.g., Wouters 2006), slow reaction, or the conservatism of some investors when accepting new information as important or valid (e.g., Barberis and Shleifer 2003).Other studies have shown very efficient markets updating prices, almost immediately, in reaction to some kinds of news (see, e.g., Busse and Green 2002). In this particular case, perhaps there are few market participants who closely follow SCOTUS developments and can confidently utilize related, public information on cases to predict relevant stock price movements. Perhaps there are few market participants who closely follow sports wagering industry stocks and can confidently utilize information regarding changes in their opportunity sets. Maybe our findings are a one-time aberration with few spillover implications and it is just 
the rare intersection of SCOTUS news with a need for expertise in the sports gaming industry which produced the slack in the timing of our results.

Our results are surprising, largely because of the relatively widespread scope and easy accessibility of the information that we consider in this paper. While the full implications are unknowable, the results suggest that expertise in specialized industries and types of news might allow for informed investor opportunities which might surprise advocates of traditional market efficiency. 


\section{References}

American Gaming Association. 2017. "Brief of the American Gaming Association as Amicus Curiae In Support of Petitioners." Supreme Court of the United States, Nos. 16-476 \& 16-477. September, $5^{\text {th }}, 2017$.

Barberis, N. and Shleifer, A. 2003. "Style Investing." Journal of Financial Economics, 68: 161199.

Busse, J. A. and Green, T. C. 2002. "Market Efficiency In Real Time.” Journal of Financial Economics. 65 (3). 415-437.

Corrado, C. J. 1989. "A Nonparametric Test For Abnormal Security-Price Performance In Event Studies." Journal of Financial Economics, 23(2), 385-395.

Fama, E. F. and French, K. R. 1993. "Common Risk Factors in the Returns On Stocks and Bonds". Journal of Financial Economics. 33 (1). 3-56.

Wouters, T. I. 2006. "Style Investing: Behavioral Explanations of Stock Market Anomalies." University Library Groningen.

Wyatt, K. 2017. "Do Not Pass Go, Do Not Collect \$231 Million Dollars: How NCAA v. Governor of New Jersey Could Negatively Affect Nevada's Monopoly On Sports Betting." UNLV Gaming Law Journal, Vol. 7 (223): 223-250. 

Table 1. Timeline of Events

\begin{tabular}{|c|c|c|l|}
\hline Date & ESPN & PredictIt & Event \\
\hline $8 / 25 / 15$ & $17 \%$ & $\mathrm{n} / \mathrm{a}$ & $\begin{array}{l}\text { 3rd Circuit Court of NJ rules in favor of } \\
\text { sports leagues in appeal }\end{array}$ \\
\hline $6 / 27 / 17$ & $60 \%$ & $\mathrm{n} / \mathrm{a}$ & SCOTUS announces it will hear case \\
\hline $12 / 3 / 17$ & $54 \%$ & $74 \%$ & Day before oral arguments \\
\hline $12 / 4 / 17$ & $67 \%$ & $87 \%$ & $\begin{array}{l}\text { SCOTUS holds oral arguments - most } \\
\text { experts conclude it was favorable to NJ }\end{array}$ \\
\hline $5 / 6 / 13$ & & $89 \%$ & Week before Decision \\
\hline $5 / 14 / 18$ & & & SCOTUS decision striking down PASPA \\
\hline
\end{tabular}


Table 2. Full sample and subsample descriptions

This table provides the full sample and various subsamples of gaming stocks noted in the popular investment press discussing ramifications of possible Supreme Court findings regarding PASPA. The twelve stocks noted here were all named in various publications in anticipation of how stock prices might react in the wake of a Supreme Court ruling. While this list is not necessarily exhaustive of all potential gaming stocks impacted by the Supreme Court's PASPA opinion, it lists all stocks noted explicitly by commentators from a thorough internet search of financial news regarding PASPA and the Supreme Court. Dozens of publications note these twelve stocks as potentially impacted, and many note special subgroups to watch which we utilize here. The publication subgroup lists we explicitly utilize are: Wall Street Journal, ESPN Business, Nasdaq, $C N B C$, investors.com and a blog covering stocks in the gaming industry, namely BettingUSA.com. In subsequent tables we analyze event-day reactions of the full sample and subgroups in response to the Supreme Court's decision to grant certiorari on the PASPA case (Murphy $v$. NCAA) on June $27^{\text {th }}, 2017$; the day of oral argument before the Supreme Court, after which legal experts offered (generally correct) predictions of likely outcomes of the case (on December $4^{\text {th }}, 2017$ ); and on the day of the Supreme Court's official opinion of the case ruling PASPA unconstitutional (May $\left.14^{\text {th }}, 2018\right)$.

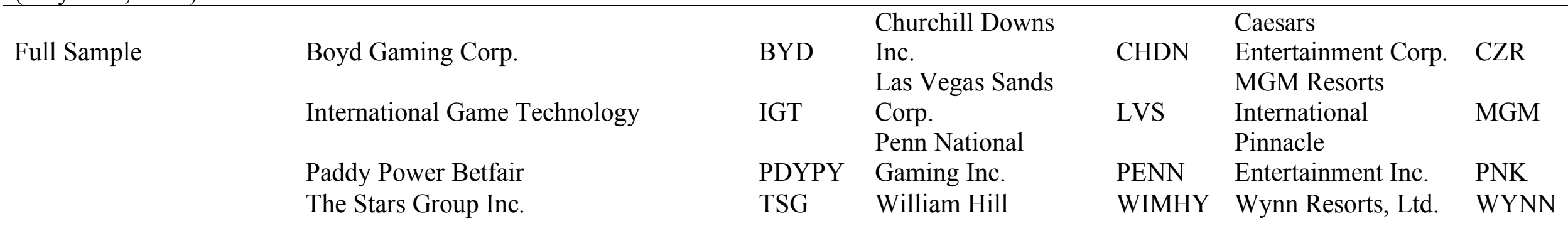

Subgroup 1

Subgroup 2

Subgroup 3

Subgroup 4

Subgroup 5

Subgroup 6
Nasdaq.com and wsj.com list of potential gainers of ruling PASPA unconstitutional, emphasizing regional players: $B Y D, C H D N, T S G$

Investors.com and cnbc.com list of potential gainers of ruling PASPA unconstitutional, emphasizing regional players: $B Y D, C Z R, P E N N$

Betting industry blog list of stocks to watch with the ruling of PASPA as unconstitutional: $B Y D, C H D N, I G T, M G M, T S G$, WIMHY, WYNN

ESPN.com international gaming stocks listed as potential gainers with the ruling of PASPA as unconstitutional: PDYPY, WIMHY

Highest five US gross gaming revenue stocks of 2017 (cut at 5 as 6 th place is $60 \%$ of 5 th place) $B Y D, C Z R, M G M, P E N N, P N K$

Highest four US stocks of 2017 for \% of total revenue from US gaming (cut at 4 as 5 th place is $70 \%$ of 4 th place) $B Y D, C H D N, P E N N, P N K$ 

Table 3. Event-day impact for the grant of certiorari

This table provides results of event-day performance of gaming stocks on the day of the Supreme Court's grant of certiorari (formal hearing) of Murphy v. NCAA considering the constitutionality of PASPA (June $27^{\text {th }}, 2017$ ). We consider a full sample and various subsamples of gaming stocks noted in the popular investment press discussing ramifications of possible Supreme Court findings regarding PASPA (see Table 2 for details on the sample and subgroups). For robustness, we measure abnormal returns on the event day via two different approaches, each based on a $(-121,-1)$ estimation window. We consider a market model correcting each day's return of each gaming stock for the S\&P 500 performance on that day and a Fama-French (1993) three-factor model which additionally corrects for relative size and book-to-market factors each day. To test for the statistical significance of abnormal returns we employ the non-parametric rank test advocated by Corrado (1989) which corrects for the event-day clustering (simultaneous event) across the stocks of the full sample and the various subgroups, thus mitigating concerns of cross-sectional correlation. The teststatistic of the Corrado (1989) follows the traditional Z-distribution. The average relative volume of the full sample and subgroup of stocks, relative to that seen in the prior 120 days, is shown (such that $100 \%$ would be an average volume day). ${ }^{*}$ denotes statistical significance at the $10 \%$ level.

\begin{tabular}{|c|c|c|c|}
\hline & $\begin{array}{l}\text { Avg. event-day } \\
\text { abnormal return w/ } \\
\text { market model }\end{array}$ & $\begin{array}{l}\text { Avg. event-day abnormal } \\
\text { return w/ Fama-French model }\end{array}$ & $\begin{array}{l}\% \text { of volume on event day } \\
\text { relative to average volume } \\
\text { days }(-121,-1)\end{array}$ \\
\hline $\begin{array}{r}\text { Full Sample } \\
\text { test-stat }\end{array}$ & $\begin{array}{r}-0.0055 \\
(-0.85)\end{array}$ & $\begin{array}{r}-0.0027 \\
(-0.14)\end{array}$ & $102.47 \%$ \\
\hline $\begin{array}{r}\text { Subgroup } 1 \\
\text { test-stat }\end{array}$ & $\begin{array}{r}-0.0102 \\
(-1.16)\end{array}$ & $\begin{array}{r}-0.0165 \\
(-1.52)\end{array}$ & $119.79 \%$ \\
\hline $\begin{array}{r}\text { Subgroup } 2 \\
\text { test-stat }\end{array}$ & $\begin{array}{r}-0.0103 \\
(-1.48)\end{array}$ & $\begin{array}{r}-0.0096 \\
(-0.87)\end{array}$ & $119.79 \%$ \\
\hline $\begin{array}{r}\text { Subgroup } 3 \\
\text { test-stat }\end{array}$ & $\begin{array}{r}-0.0067 \\
(-0.39)\end{array}$ & $\begin{array}{r}-0.0042 \\
(-0.31)\end{array}$ & $104.94 \%$ \\
\hline $\begin{array}{r}\text { Subgroup } 4 \\
\text { test-stat }\end{array}$ & $\begin{array}{c}-0.0034 \\
(-0.12)\end{array}$ & $\begin{array}{l}0.0063 \\
(0.02)\end{array}$ & $61.24 \%$ \\
\hline $\begin{array}{l}\text { Subgroup } 5 \\
\text { test-stat }\end{array}$ & $\begin{array}{l}-0.0115 \\
(-1.39)\end{array}$ & $\begin{array}{c}-0.0094 \\
(-0.66)\end{array}$ & $104.94 \%$ \\
\hline $\begin{array}{r}\text { Subgroup } 6 \\
\text { test-stat }\end{array}$ & $\begin{array}{r}-0.0135 \\
(-1.39)\end{array}$ & $\begin{array}{c}-0.0189^{*} \\
(-1.80)\end{array}$ & $98.17 \%$ \\
\hline
\end{tabular}


Table 4. Event-day impact for oral argument

This table provides results of event-day performance of gaming stocks on the day of the Supreme Court's oral argument of Murphy v. NCAA considering the constitutionality of PASPA (December 4, 2017). The tone and questions of Supreme Court justices are thought to be, in some cases, indicative of the likely decision of the Court, and many commentators (correctly) anticipated the eventual ruling of PASPA as unconstitutional after oral argument. We consider a full sample and various subsamples of gaming stocks noted in the popular investment press discussing ramifications of possible Supreme Court findings regarding PASPA (see Table 2 for details on the sample and subgroups). For robustness, we measure abnormal returns on the event day via two different approaches, each based on a $(-121,-1)$ estimation window. We consider a market model correcting each day's return of each gaming stock for the S\&P 500 performance on that day and a Fama-French (1993) three-factor model which additionally corrects for relative size and book-to-market factors each day. To test for the statistical significance of abnormal returns we employ the non-parametric rank test advocated by Corrado (1989) which corrects for the event-day clustering (simultaneous event) across the stocks of the full sample and the various subgroups, thus mitigating concerns of cross-sectional correlation. The test-statistic of the Corrado (1989) follows the traditional Zdistribution. The average relative volume of the full sample and subgroup of stocks, relative to that seen in the prior 120 days is shown (such that $100 \%$ would be an average volume day). ${ }^{* *}$ denotes statistical significance at the 5\% level.

\begin{tabular}{|c|c|c|c|}
\hline & $\begin{array}{l}\text { Avg. event-day } \\
\text { abnormal return w/ } \\
\text { market model }\end{array}$ & $\begin{array}{l}\text { Avg. event-day abnormal } \\
\text { return w/ Fama-French } \\
\text { model }\end{array}$ & $\begin{array}{l}\% \text { of volume on event day } \\
\text { relative to average volume } \\
\text { days }(-121,-1)\end{array}$ \\
\hline $\begin{array}{r}\text { Full Sample } \\
\text { test-stat }\end{array}$ & $\begin{array}{c}0.0016 \\
(0.33)\end{array}$ & $\begin{array}{c}0.0036 \\
(0.96)\end{array}$ & $99.17 \%$ \\
\hline $\begin{array}{l}\text { Subgroup } 1 \\
\text { test-stat }\end{array}$ & $\begin{array}{c}0.0077 \\
(1.31)\end{array}$ & $\begin{array}{c}0.0079 \\
(1.63)\end{array}$ & $177.73 \%$ \\
\hline $\begin{array}{l}\text { Subgroup } 2 \\
\text { test-stat }\end{array}$ & $\begin{array}{c}-0.0083 \\
(-0.85)\end{array}$ & $\begin{array}{c}-0.0027 \\
(-0.12)\end{array}$ & $165.69 \%$ \\
\hline $\begin{array}{r}\text { Subgroup } 3 \\
\text { test-stat }\end{array}$ & $\begin{array}{c}0.0058 \\
(0.80)\end{array}$ & $\begin{array}{l}0.0070^{* *} \\
\quad(2.02)\end{array}$ & $165.69 \%$ \\
\hline $\begin{array}{r}\text { Subgroup } 4 \\
\text { test-stat }\end{array}$ & $\begin{array}{c}0.0103 \\
(1.04)\end{array}$ & $\begin{array}{c}0.0120 \\
(1.18)\end{array}$ & $115.34 \%$ \\
\hline $\begin{array}{l}\text { Subgroup } 5 \\
\text { test-stat }\end{array}$ & $\begin{array}{l}-0.0039 \\
(-0.45)\end{array}$ & $\begin{array}{c}0.0013 \\
(0.33)\end{array}$ & $102.29 \%$ \\
\hline $\begin{array}{r}\text { Subgroup } 6 \\
\text { test-stat }\end{array}$ & $\begin{array}{c}0.0017 \\
(0.14)\end{array}$ & $\begin{array}{c}0.0039 \\
(0.78)\end{array}$ & $133.99 \%$ \\
\hline
\end{tabular}


Table 5. Event-day impact for decision

This table provides results of event-day performance of gaming stocks on the day of the Supreme Court's opinion announcement (decision) of Murphy v. NCAA declaring the unconstitutionality of PASPA (May 14 ${ }^{\text {th }}, 2018$ ). We consider a full sample and various subsamples of gaming stocks noted in the popular investment press discussing ramifications of possible Supreme Court findings regarding PASPA (see Table 2 for details on the sample and subgroups). For robustness, we measure abnormal returns on the event day via two different approaches, each based on a $(-121,-1)$ estimation window. We consider a market model correcting each day's return of each gaming stock for the S\&P 500 performance on that day and a Fama-French (1993) three-factor model which additionally corrects for relative size and book-to-market factors each day. To test for the statistical significance of abnormal returns we employ the non-parametric rank test advocated by Corrado (1989) which corrects for the event-day clustering (simultaneous event) across the stocks of the full sample and the various subgroups, thus mitigating concerns of cross-sectional correlation. The test-statistic of the Corrado (1989) follows the traditional Z-distribution. The average relative volume of the full sample and subgroup of stocks, relative to that seen in the prior 120 days is shown (such that $100 \%$ would be an average volume day). ** denotes statistical significance at the $5 \%$ level.

\begin{tabular}{|c|c|c|c|}
\hline & $\begin{array}{l}\text { Avg. event-day } \\
\text { abnormal return w/ } \\
\text { market model }\end{array}$ & $\begin{array}{l}\text { Avg. event-day abnormal } \\
\text { return w/ Fama-French } \\
\text { model }\end{array}$ & $\begin{array}{l}\% \text { of volume on event day } \\
\text { relative to average volume } \\
\text { days }(-121,-1)\end{array}$ \\
\hline $\begin{array}{r}\text { Full Sample } \\
\text { test-stat }\end{array}$ & $\begin{array}{c}0.0472^{* *} \\
(2.14)\end{array}$ & $\begin{array}{c}0.0481 * * \\
(2.25)\end{array}$ & $157.73 \%$ \\
\hline $\begin{array}{r}\text { Subgroup } 1 \\
\text { test-stat }\end{array}$ & $\begin{array}{l}0.0555^{* *} \\
(2.37)\end{array}$ & $\begin{array}{l}0.0568 * * \\
(2.40)\end{array}$ & $319.14 \%$ \\
\hline $\begin{array}{l}\text { Subgroup } 2 \\
\text { test-stat }\end{array}$ & $\begin{array}{l}0.0431 * * \\
(2.29)\end{array}$ & $\begin{array}{l}0.0440 * * \\
(2.30)\end{array}$ & $283.26 \%$ \\
\hline $\begin{array}{r}\text { Subgroup } 3 \\
\text { test-stat }\end{array}$ & $\begin{array}{c}0.0477 \\
(1.12)\end{array}$ & $\begin{array}{c}0.0484 \\
(1.25)\end{array}$ & $283.26 \%$ \\
\hline $\begin{array}{r}\text { Subgroup } 4 \\
\text { test-stat }\end{array}$ & $\begin{array}{c}0.1339 * * \\
(2.15)\end{array}$ & $\begin{array}{l}0.1348 * * \\
(2.23)\end{array}$ & $487.73 \%$ \\
\hline $\begin{array}{r}\text { Subgroup } 5 \\
\text { test-stat }\end{array}$ & $\begin{array}{l}0.0326^{* *} \\
(2.33)\end{array}$ & $\begin{array}{l}0.0332 * * \\
(2.27)\end{array}$ & $277.72 \%$ \\
\hline $\begin{array}{r}\text { Subgroup } 6 \\
\text { test-stat }\end{array}$ & $\begin{array}{l}0.0354 * * \\
(2.19)\end{array}$ & $\begin{array}{l}0.0366^{* *} \\
(2.23)\end{array}$ & $280.49 \%$ \\
\hline
\end{tabular}

